\title{
Genetic algorithm based PID controller design for a multi-area AGC scheme in a restructured power system
}

\author{
Sandeep Bhongade*1 ${ }^{*}$ Barjeev Tyagi ${ }^{* 2}$, H. O. Gupta ${ }^{* 3}$ \\ *Electrical Engineering Department, Indian Institute of Technology, Roorkee, INDIA \\ "Corresponding Author: e-mail: 'bhongadesandeep@gmail.com, Tel +91-1332-285555, Fax.+911332-286691
}

\begin{abstract}
In this paper, a multi-area Automatic Generation Control (AGC) scheme suitable in a restructured interconnected power system has been proposed. Developed scheme utilizes a proportional, integral and derivative (PID) controller to control the output of the generators. The parameter of PID controller has been tuned according to Genetic Algorithm (GA) based performance indices. Developed model also include the Superconducting Magnetic Energy Storage (SMES) units to inject or absorb the active power of an interconnected power system. The functioning of Genetic Algorithm based PID controller has been tested on a 39-bus New England system and 75-bus Indian power system network. The results of GAPID controller have been compared with those obtained by using the Least Square Minimization method. Compliance with North American Electric Reliability Council (NERC) standards for AGC has also been established in this work.
\end{abstract}

Keywords: Genetic Algorithms, Automatic Generation Control, Area control error, Superconducting magnetic energy storage (SMES), Control Performance Standards.

\section{Introduction}

In interconnected power systems the main goal of the AGC is to maintain zero steady state errors for frequency deviation and good tracking load demands. With time, the operating point of a power system changes and hence, these systems may experience deviations in nominal system frequency and scheduled power exchanges to other areas, which may yield undesirable effects. In conventional AGC model the variations of frequency and tie-line power exchanges are weighted together by a linear combination to a single variable called the area control error (ACE). ACE is used as an input to the controller. Many investigations in the area frequency and tie line control of isolated and interconnected power systems have been reported in the past. The concept of conventional AGC is discussed in Elgerd et al. (1970) and in Jaleeli et al. (1992).

Around the world, the electric power industry has been undergoing reforms from the traditional regulated, vertically integrated utility (VIU) into a competitive, deregulated market. Market deregulation has caused significant changes not only in the generation sector, but also in the power transmission and distribution sectors. A detailed discussion on Load Frequency Control issues in power system operation after deregulation is reported in Christie and Bose (1996). The load frequency control in a deregulated electricity market should be designed to consider different types of possible transactions such as Poolco-based transactions, bilateral transactions, and a combination of these two.

After the deregulation of the electricity sector, North American Electric Reliability Council (NERC) has modified the control performance standard (CPS) for AGC. Maojun et al. (2000) have proposed a new AGC logic which is specifically designed to work under NERC performance standards. In Sasaki and Enomoto et al. (2002), the NERC standard to the Japanese power system and analyzed the compliance of their AGC scheme to these standards.

The reliability of electric power supply during peak load period can be improved by using a battery energy storage system (BES). Energy is stored into the BES during off-peak load period and released from the BES during peak load period. In Shayeghi et al. (2008) the SMES units in each area of the two-area system for AGC has been considered. With the use of SMES units, frequency deviations in each area are effectively suppressed. However, it may not be economically feasible to use SMES unit in 
every area of a multi-area system. Therefore, it is advantageous if an SMES unit located in an area is available for the control of frequency of other interconnected areas. In Automatic Generation Control (AGC) PID controller is widely used to control the frequency and tie-line power. Many researchers (Khamsum et al., 2006; Tyagi et al., 2008) have proposed different methods to tune the PID controller; one of them is the least square minimization method. An optimal value of PID controller using Least Square Minimization problem has been proposed in Al-Saggaf et al. (1991). Genetic algorithms are more likely to converge to global optima than conventional Least Square Minimization Techniques: since they search from a population of points and are based on probabilistic transition rules. This minimization technique is ordinarily based on gradient descent methods, which, by definition, will only find local optima. Genetic algorithms can also tolerate discontinuities and noisy function evaluations. In the present work effect of SMES unit and GRC are also included. This introduces the non-linearity in the system for such a system conventional minimization technique does not give the effective results. Therefore, GA based PID controller tuning is considered in the present work.

In this work, first a multi-area AGC scheme suitable in a restructured power system has been developed then a Genetic Algorithm based PID (GAPID) controller has been proposed for this multi area AGC scheme. The proposed method of controller tuning implemented in an interconnected two areas and four area power systems. MATLAB SIMULINK has been used for simulation studies. By minimizing the fitness function we get the optimal parameters of PID controller. Integral of the square of the area control error (ISACE) have been utilized to select the fitness function for genetic algorithm. The population size 50 has been chosen for genetic algorithm to obtain the optimal values of PID controller.

The proposed GAPID based AGC scheme has been tested on a practical 39-bus New England system divided into two control areas and a 75-bus Indian power system divided into four control areas. A deregulated electricity market scenario has been assumed in both systems. The effect of generator rate constraint (GRC) has also been considered in the multi area AGC model. A combination of bilateral transactions and Poolco-based transactions has been considered, and it has been assumed that both the generators and the consumers are participating in the frequency regulation market. Simulation results show that the proposed GAPID Controller complies with NERC's standards. The performance studies have been carried out by using the MATLAB SIMULINK for transactions within and across the control area boundaries.

\section{System Modeling}

Electricity reforms are being brought to introduce commercial incentives in generation, transmission, distribution and retailing of electricity, with resultant efficiency gain, in many cases. Introduction of competition in electricity market may cause emergence of several new entities, such as Generating companies (Gencos), Transmission companies (Transcos), Distribution companies (Discos) and system operator (SO). The system operator is an entity entrusted with the responsibility of ensuring the reliability and security of the power system. It is an independent entity and does not participate in the electricity trading. In order to maintain the system security and reliability, the SO procures various services, such as supply of emergency reserves, frequency regulation and reactive power from the other entities in the system. These services are known as the 'ancillary services' (Jayant Kumar et al, 1997).

\section{A. Poolco based transaction}

In Poolco based transaction, the Discos and Gencos of the same area participate in the frequency regulation through system operator. System operator (SO) accepts bids (volume and price) from power producers (Gencos) who are willing to quickly (with in about 10-15 minutes) increase or decrease their level of production. Consumers (Discos) also can submit bids to SO for increasing or decreasing their level of consumption. In each hour of operation, the SO activates the most favorable bid. If the frequency is lower than nominal value, up regulation bids are activated by the System Operator in steps and the highest activated bid becomes the regulation price, uniformly paid to all the providers of upward regulation service. If the frequency is higher than nominal, down regulation is activated by the System Operator in steps and the lowest activated bid price becomes the uniform price, to be paid by all the down regulation service providers. Thus, the hourly regulating price is fixed as the price for the most expensive measure (regulating up) or least expensive measure (regulating down) utilized during the hour. At the end of scheduled interval, the net energy balance of each entity is calculated and financial settlements are carried out.

\section{B. Participation factor of a Genco and Disco in Frequency Regulation Market}

Let there be $n$ number of power producers and $m$ number of consumers in area-i participating in the market. Assume that the bids submitted by the power producers and consumers, for frequency regulation are $(\operatorname{pg}(1), \operatorname{cg}(1)),(\operatorname{pg}(2), \operatorname{cg}(2)), \ldots \ldots,(\operatorname{pg}(\mathrm{n}), \operatorname{cg}(\mathrm{n}))$ and $(\mathrm{pl}(1), \mathrm{cl}(1)),(\mathrm{pl}(2), \mathrm{cl}(2)), \ldots \ldots \ldots \ldots \ldots,(\mathrm{pl}(\mathrm{m}), \mathrm{cl}(\mathrm{m}))$, respectively given in Tyagi et al (2008), Where, $\mathrm{pg}(\mathrm{i})$ is the price for regulating power quoted by $i^{\text {th }}$ Genco for upward regulation, $\operatorname{cg}(i)$ is the capacity quoted by $i^{\text {th }}$ Genco for upward regulation, $i=1$, $2 \ldots \mathrm{n}, \mathrm{pl}(\mathrm{j})$ is the price for regulating power quoted by jth Disco for upward regulation, cl (j) is the capacity quoted by jth Disco for upward regulation, $j=1,2 \ldots \mathrm{m}$. If Tdem is the total extra demand that arises in the hour of operation in any area for upward regulation, the participation factor of each Genco and Disco in that area can be calculated by minimizing the cost of regulating power, 


$$
\operatorname{Creg}=\sum_{i=1}^{n} p g(i) * \operatorname{gen}(i)+\sum_{j=1}^{m} p l(j) * \operatorname{load}(j)
$$

Subject to a set of constraints

$\operatorname{gen}(i)+\operatorname{load}(j)=\operatorname{Tdem}$

$\operatorname{gen}(i) \leq \operatorname{cg}(i)$

$\operatorname{load}(j) \leq \operatorname{cl}(j)$

Where, gen (i) is the change in the power generated by the $i^{\text {th }}$ Genco, load $(j)$ is the loads curtailed by the $j^{\text {th }}$ Disco. Although the price for the up regulating power is the maximum bid price selected to generate the power for frequency regulation, but the Gencos quoting the minimum price area allowed generating the maximum power. Participation factor of the $\mathrm{i}^{\text {th }}$ Genco for up regulation can be defined as,

$$
p f g(i)=\frac{g e n(i)}{T d e m}
$$

And the participation factor of the $\mathrm{j}^{\text {th }}$ Disco for up regulation can be defined as,

$$
p f d(j)=\frac{\operatorname{load}(j)}{\operatorname{Tdem}}
$$

For down regulation, the participation factor of each Genco as well as Disco in any area can be calculated by maximizing the cost of the regulating power defined as,

$$
\text { cdreg }=\sum_{i=1}^{n} p g(i) * \operatorname{regn}(i)+\sum_{j=1}^{m} p l(j) * u \operatorname{load}(j)
$$

Where, regn (i) is the reduction in the power output of the $i^{\text {th }}$ Genco, uload (j) is the increase in the load by the $j^{\text {th }}$ Disco, Tdem is the reduction in the total load demand in the area. Participation factor of the $i^{\text {th }}$ Genco for down regulation can be defined as,

$$
p f g(i)=\frac{\operatorname{regn}(i)}{\text { Tdem }}
$$

And the participation factor of the $\mathrm{j}^{\text {th }}$ Disco for down regulation can be defined as,

$$
p f d(j)=\frac{u \operatorname{load}(j)}{\operatorname{Tdem}}
$$

\section{Bilateral transactions}

In bilateral transaction, Gencos and Discos negotiate bilateral contracts among each other and submit their contractual agreements to a system operator (SO). The players are responsible for having a communication path to exchange contract data as well as measurements to do load following in real-time. In such an arrangement, a Disco sends a pulse to Genco to follow the predicted load as long as it does not exceed the contracted value. The responsibility of the Disco is to monitor its load continuously and ensure the loads following requirements are met according to the contractual agreement. A detailed discussion on bilateral transactions is given in Donde et al (2001).

In this work, bilateral transactions within the area and across the area have been considered. Disco of one area can contract to the Genco of same area or other area to supply a certain amount of power in a specified time interval. These bilateral contracts can be represented in the matrix form in which the number of rows equal to the number of Gencos and column equal to the number of Discos in the system. The elements of this Contract Matrix (CM) represent the percentage load demand of one Disco to different Gencos. Let us consider a Contract Matrix as given below: 


$$
C M=\left[\begin{array}{ccccc}
0 & 10 & \cdots & \ldots & \cdots \\
20 & 10 & \vdots & \vdots & \vdots \\
10 & \vdots & & & \\
\vdots & \vdots & \ldots & \ldots & \vdots \\
0 & 0 & & &
\end{array}\right]
$$

For example, the first column of CM represents the Disco D1 bilateral contract with different Gencos. Element $\mathrm{CM}_{21}$ is 20 which means $20 \%$ of total demand of Disco D1 in the schedule time interval will be supplied by the Genco G2. Sum of the elements of any column represents the percentage of total demand of that Disco which will be supplied by the bilateral contracts. Rest of the demand will be supplied by the Poolco transactions.

In case of Poolco transaction tie-line power between area-i and area-j is settled at zero value. But in case of bilateral transition the tie-line power is not settled at zero value but settled according to the bilateral contract between Gencos of one area and Discos of other area.

\section{Calculation of Area Control Error (ACE)}

In a practical multi area power system, a control area is interconnected to its neighboring areas with tie lines, all forming part of the overall power pool. If $P_{i j}$ is the tie line real power flow from an area-i to another area- $\mathrm{j}$ and $\mathrm{m}$ is the total number of areas, the net tie line power flow from area-i will be

$$
P_{t i e-i}=\sum_{\substack{j=1 \\ j \neq i}}^{m} P_{i j}
$$

In a conventional AGC formulation, $P_{t i e-i}$ is generally maintained at a fixed value. However, in a deregulated electricity market, a Disco may have contracts with the Gencos in the same area as well as with the Gencos in other areas, too. Hence, the scheduled tie-line power of any area may change as the demand of the Disco changes.

Thus, the net change in the scheduled steady-state power flow on the tie line from an area- $i$ can be expressed as

$$
\Delta P_{\text {tie-new }}=\Delta P_{\text {tie-i }}+\sum_{\substack{j=1 \\ j \neq i}}^{m} D_{i j}-\sum_{\substack{j=1 \\ j \neq i}}^{m} D_{j i}
$$

Where, $\Delta P_{t i e-i}$ is the change in the scheduled tie-line power due to change in the demand, $D_{i j}$ is the demand of Discos in area-j from Gencos in area-i and $D_{j i}$ is the demand of Discos in area- $\mathrm{i}$ from Gencos in area-j.

Generally, $\Delta P_{t i e-i}=0$,(Conventioanl AGC).During the transient period, at any given time, the tie-line power error is given as:

$$
\Delta P_{\text {tie-i-error }}=\Delta P_{\text {tie-i-actual }}-\Delta P_{\text {tie-i-new }}
$$

This error signal can be used to generate the Area Control Error (ACE) signal as:

$A C E_{i}=B_{i} \Delta f_{i}+\Delta P_{\text {tie-i-error }}$

Where, $B_{\mathrm{i}}$ is the frequency bias factor and $\Delta \mathrm{f}_{\mathrm{i}}$ is the frequency deviation in area-i.

There may be a number of Gencos in the $\mathrm{i}^{\text {th }}$ area. Fig. 1 represents the block diagram of the $\mathrm{k}^{\text {th }}$ Genco in area-i. The $p f$ is the Gencos participation factor as described in the section (B), $R_{i}$ is the droop, and $G_{g}$ and $G_{t}$ represents the transfer function model of Governor and turbine respectively, and are expressed as Elgerd et al (1970), $G_{g}=\frac{1}{1+s T_{g}}$, where $T_{g}$ is the governor time constant and $G_{t}=\frac{1}{1+s T_{t}}$, where $T_{t}$ is the turbine time constant. $\Delta P_{G 1}, \Delta P_{G 2}, \ldots \ldots \ldots, \Delta P_{G k}, \ldots \ldots . \Delta P_{G n}$ represents the change in the output of area- $i$ Gencos. The net change in area- $i$ generation is $\Delta P_{G i}=\Delta P_{G 1}+\Delta P_{G 2}+\cdots+\Delta P_{G k}+\cdots . \Delta P_{G n}$, where $n$ is the total number of Gencos in area- $i$. There may be number of Discos in the $i^{\text {th }}$ area. If $\Delta P_{D 1}, \Delta P_{D 2}, \ldots \ldots . \Delta P_{D p}, \ldots \ldots, \Delta P_{D k}$ represents the change in load demand of Discos in the area- $i$. The net load change in the $i^{\text {th }}$ area is given as $\Delta P_{D}=\Delta P_{D 1}+\Delta P_{D 2}+\cdots+\Delta P_{D p}+\cdots+\Delta P_{D L}$, where $L$ is the total number of Discos in area- $i$. 


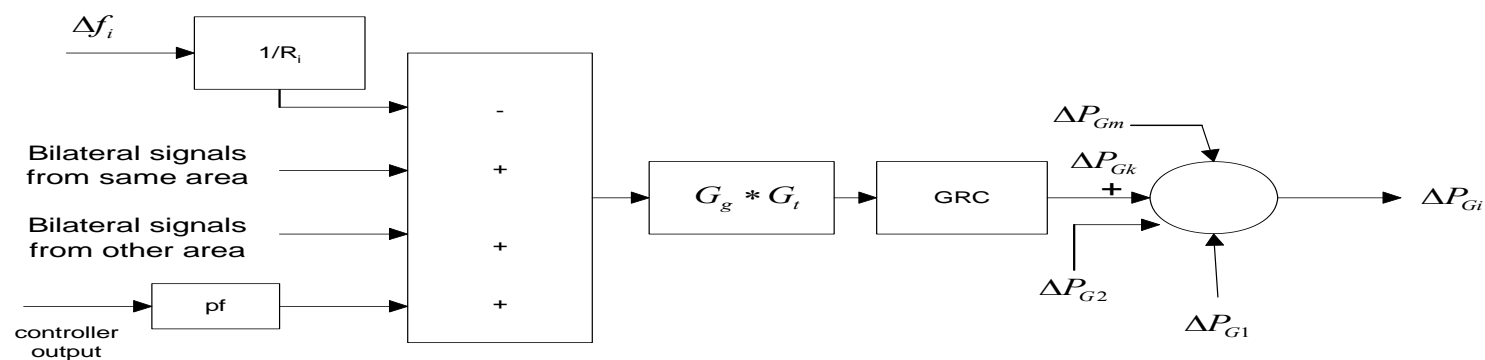

Figure 1. Block Diagram of Genco-k of area-i

\section{E. Generation Rate Constraint (GRC)}

In any practical electrical power generating system, due to thermodynamic and mechanical constraints, there is a limit to the rate at which its output power can be changed. This limit is referred to as generator rate constraint (GRC). A Saturation nonlinearity is shown in fig. 2 is considered for Generation Rate Constraint (GRC). $\mathrm{S}_{\max }$ is the maximum capacity of the generating plant. $\mathrm{S}$ is the slope representing the rate of change of generator output.

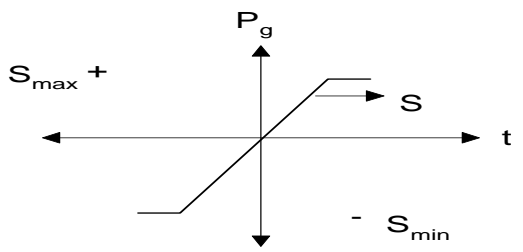

Figure 2 Saturation Nonlinearity

\section{F. SMES system}

Superconducting magnetic energy storage (SMES) system has numerous advantages in electrical power system applications. SMES units has attracted the attention of power engineers in recent years because of its extremely fast response in switching over from charging mode to discharging mode and the high rate of energy discharge capability. A detailed discussion on SMES unit is reported in Joseph R et al (2007). A brief discussion on SMES unit is given below:

The schematic diagram in Fig. 3 shows the configuration of a thyristor controlled SMES unit. The SMES inductor-converter unit consists of a dc superconducting inductor, a 12-pulse cascade bridge type ac/dc converter and a $\mathrm{Y}-\mathrm{Y} / \Delta$ step down transformer. Control of the converter firing angle provides the $\mathrm{DC}$ voltage $\mathrm{E}_{\mathrm{d}}$ appearing across the inductor to be continuously varied between a wide range of positive and negative values. Charging and discharging are controlled through simple change of commutation angle $(\gamma)$.

- If $\gamma<90^{\circ}$ converter acts in the converter mode (charging mode)

- If $\gamma>90^{\circ}$ converter acts in the inverter mode( discharging mode)

Since the bridge current $I_{d}$ is not reversible, the bridge output power $P_{S M}$ is uniquely a function of firing angle, which can be positive or negative. Whenever a load variation occurs in the system, the high-speed thyristor-controlled SMES system is set into dynamic operation to minimize $\Delta \mathrm{f}$ as soon as possible. This is done by varying the input to the SMES unit so as to vary its power $P_{S M}$. If $E_{d}$ is positive, power is transffered from the power system to the SMES unit and if $E_{d}$ is negative, power is released from the SMES unit. The energy stored in the superconducting inductor is

$$
E_{S M}=E_{S M O}+\int_{t o}^{t} P_{S M}(\tau) d \tau
$$

Where, $E_{S M O}=\frac{1}{2} L_{d o}^{2}$ is the initial energy in the inductor. The inductor is initially charged to its rated current $\mathrm{I}_{\mathrm{d} 0}$ by applying a low positive voltage. Once the current reaches the rated value, it is maintained constant by reducing the voltage across the inductor to zero since the coil is superconducting.

Neglecting the transformer and the converter losses, the DC voltage is given by

$E_{d}=2 U_{d o} \cos \gamma-2 I_{d} R_{c}$

where $E_{d}$ is DC voltage applied to the inductor $(k V), \gamma$ is firing angle (degrees), $I_{d}$ is current flowing through the inductor $(k A), R_{c}$, is equivalent commutating resistance $(\Omega)$ and $\mathrm{U}_{\mathrm{dO}}$ is maximum circuit bridge voltage $(\mathrm{kV})$. 


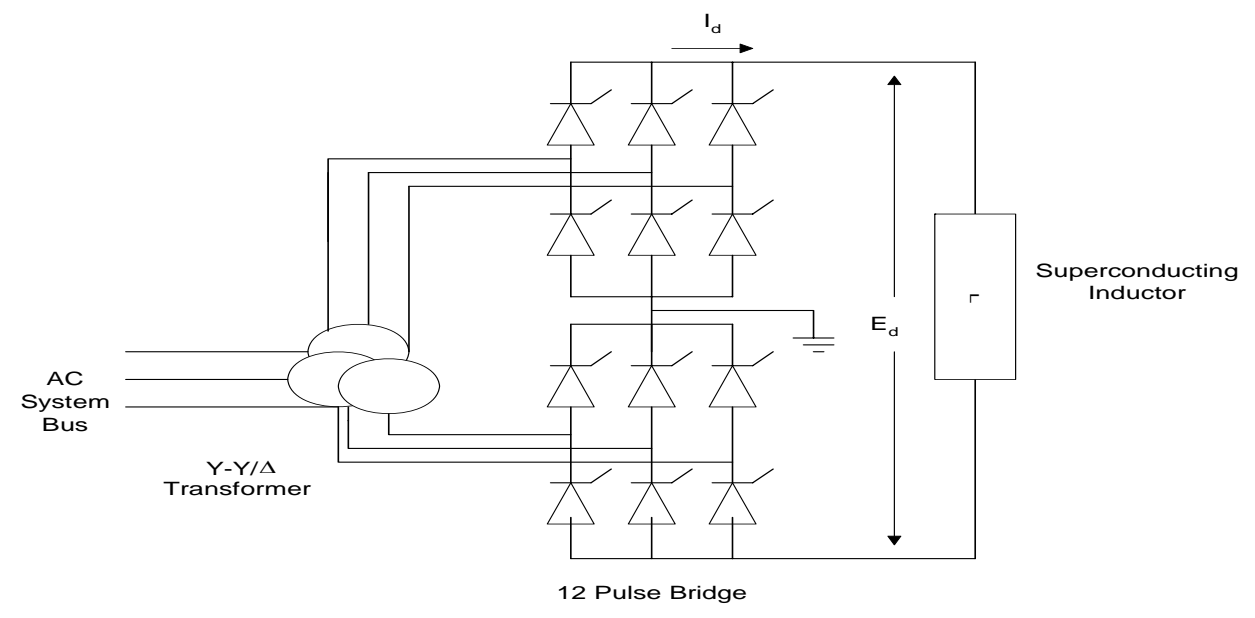

Figure 3 SMES unit

\section{(i) Frequency Deviation as a control signal}

The frequency deviation $\Delta \mathrm{f}$ of the power system is sensed and used to control the SMES voltage, $\mathrm{E}_{\mathrm{d}}$. When power is pumped back into the interconnected system in the case of fall in frequency due to sudden loading in the area, the control voltage $E_{d}$ is to be negative, since the current through the inductor and the thyristors cannot change its direction. The incremental change in the voltage applied to the inductor is expressed as:

$$
\Delta E_{d}=\left[\frac{K_{S M E S}}{1+s T_{d c}}\right] \Delta f_{i}
$$

Where, $\Delta E_{d}$ is the incremental change in the converter voltage, $T_{d c}$ is the converter time delay, $K_{S M E S}(\mathrm{KV} / \mathrm{Hz})$ is the gain of the control loop and's' is the Laplace operator .

\section{(ii) Area Control Error (ACE) as a control signal}

In an interconnected power system, it is desirable to use Area Control Error (ACE) as input to SMES control logic. The ACE signal as defined in equation (13) for area-i. If ACE is directly used for the control of SMES, the gain constant $K_{S M E S}$ (KV/unit $\mathrm{ACE}$ ) would be totally different from the gain constant for frequency deviation as control signal. So as signal proportional to area control error $\left(f_{i}+\frac{1}{B_{i}} \Delta P_{\text {tie-i-error }}\right)$ is used in such scheme.

Then,

$$
\Delta E_{d i}=\frac{K_{S M E S i}}{1+s T_{d c i}}\left(f_{i}+\frac{1}{B_{i}} \Delta P_{\text {tie-i-error }}\right)
$$

In this study, inductor voltage deviation of SMES unit of each area is based on ACE of the same area in power system. The inductor current deviation is used as a negative feedback signal in the SMES control loop. If the load demand changes suddenly, the feedback provides quickly restoration of current. Then with ACE is used as control signal as expressed in Tripathy S. C et al, 1992

$$
\Delta E_{d i}=\frac{K_{S M E S i}}{1+s T_{d c i}}\left[\left(f_{i}+\frac{1}{B_{i}} \Delta P_{\text {tie-i-error }}\right)-K_{i d} \Delta I_{d}\right]
$$

The block diagram representation of SMES control scheme is shown in fig 4 ( Joseph $\mathrm{R}$ et al ,2007). 


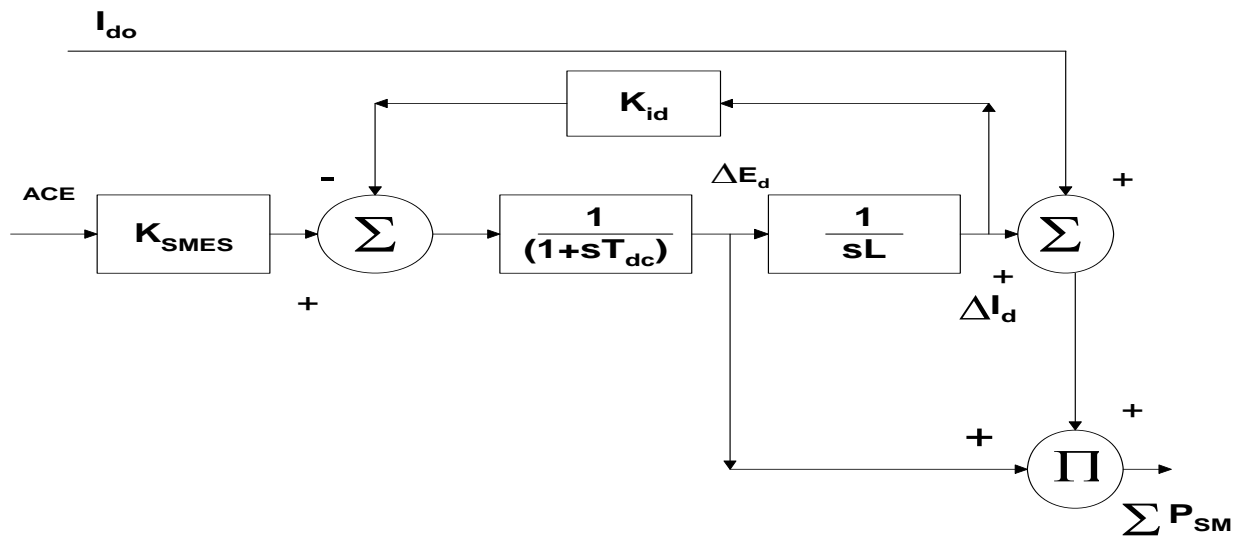

Figure 4 SMES control scheme

The overall block diagram of AGC scheme including SMES unit and Generation Rate Constraint for an $\mathrm{i}^{\text {th }}$ area of $\mathrm{m}$-area power system is shown in fig.5.The power system block represents the power system dynamics given by $\frac{K_{p i}}{1+s T_{p i}}$, where $K_{p i}$ is the system gain and is equivalent to $1 / D_{i}$ where $D_{i}$ is the rate of change of load demand $\Delta P_{D}$ to the change in frequency $\Delta f$ and is expressed in $\mathrm{Hz} / \mathrm{pu} \mathrm{MW}$ and $T_{p i}$ is the time constant and is equivalent to $2 H_{i} /\left(f^{*} D_{i}\right)$ where, the parameter $H_{i}$ is the per -unit inertia constant. In fig. $5 \Delta P_{D}$ is the total demand of area-i. The part of area demand is fulfilled by bilateral transactions, and the rest of the demand will be arranged by the system operator through Poolco-based contracts.

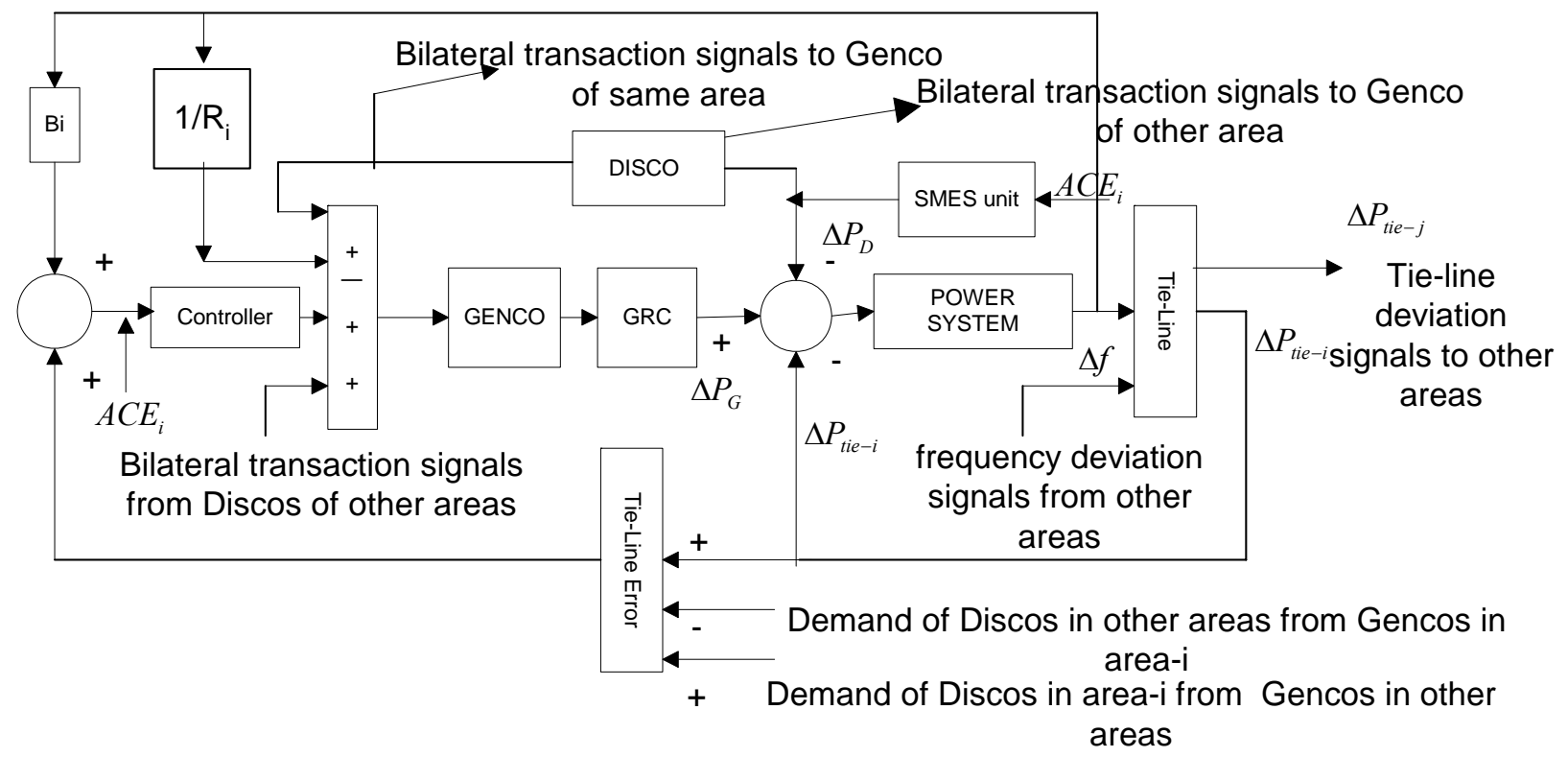

Figure 5. AGC Block Diagram For Area-i

\section{PID controller tuning using genetic algorithm (GA)}

The form of a PID controller can be expressed as the sum of three terms, proportional, integral, and derivative control. The transfer function of such a PID controller can be expressed as:

$$
\mathrm{G}_{\mathrm{C}}(\mathrm{s})=\mathrm{K}_{\mathrm{P}}+\frac{\mathrm{K}_{\mathrm{I}}}{\mathrm{s}}+\mathrm{K}_{\mathrm{D}} \mathrm{s}
$$

Where, $K_{P}, K_{I}, K_{D}$ are the proportional, integral and derivative gain constant of the controller. Optimal values of $K_{P}, K_{I}, K_{D}$ can be determined by many ways, one of them, is suggested by the Donde et al. A Genetic Algorithm based minimization approach to determine the values of $K_{P}, K_{I}, K_{D}$ has been developed in this work.

Genetic Algorithms are based on Darwin's theory of natural selection and survival of the fittest. It is a heuristic optimization technique for the most optimal solution (fittest individual) from a global perspective but more importantly, it provides a 
mechanism by which solutions can be found to complex optimization problems fairly quickly and reliably. Following are the important terminology in connection with the genetic algorithm as given in Goldberg D.E (1989):

Individual - An individual is any point to which objective function can be applied. It is basically the set of values of all the variables for which function is going to be optimized. The value of the objective function for an individual is called its score. An individual is sometimes referred to as a genome and the vector entries of it as genes.

Population - It is an array of individuals. For example, if the size of the population is 100 and the number of variables in the objective function is 3, population can be represented by a 100-by-3 matrix in which each row correspond to an individual.

Generation - at each iteration, the genetic algorithm performs a series of computations on the current population to produce a new population by applying genetic operators. Each successive population is called a new generation.

Parents and children - To create the next generation, the genetic algorithm selects certain individuals in the current population, called parents, and uses them to create individuals in the next generation, called children. Following three genetic operators are applied on parents to form children for next generation:

1. Reproduction - Selects the fittest individuals in the current population to be used in generating the next population. The children are called Elite children.

2. Cross-over - Causes pairs of individuals to exchange genetic information with one another. The children are called Crossover children.

3. Mutation - Causes individual genetic representations to be changed according to some probabilistic rule. The children in this case are called Mutation children.

In GA's the value of fitness represents the performance which is used to rank 0 and the ranking is then used to determine how to allocate reproductive opportunities. This means that individual with a higher fitness value will have a higher opportunity of being selected as a parent. The fitness function is essentially the objective function for the problem. Interconnected power system model as shown in Fig. 5 has been created in MATLAB Simulink. Area Control Error (ACE) for each area is calculated by running this model with PID controller. Initially, parameters $\left(\mathrm{K}_{\mathrm{P}}, \mathrm{K}_{\mathrm{I}}, \mathrm{K}_{\mathrm{D}}\right)$ of PID controller area selected using Least Square Minimization method, which gives stable results. ACE is further minimized using the GA optimization toolbox GAOT in MATLAB proposed by Houck et al (1995) to obtain the optimal PID parameters. The complete algorithm is described below:

Minimize (Integral of square of the Area Control Error)

$$
I S A C E=\int \sum_{i=1}^{m}\left(A C E_{i}\right)^{2}
$$

Where, $m$ is the number of area in the system.

Subjected to

$$
\begin{aligned}
& K_{P, i}^{\min } \leq K_{P, i} \leq K_{P, i}^{\max } \\
& K_{I, i}^{\text {min }} \leq K_{I, i} \leq K_{I, i}^{\text {max }} \\
& K_{D, i}^{\text {min }} \leq K_{D, i} \leq K_{D, i}^{\max }
\end{aligned}
$$

Where, $\mathrm{K}_{\mathrm{P}, \mathrm{i}}, \mathrm{K}_{\mathrm{I}, \mathrm{i}}, \mathrm{K}_{\mathrm{D}, \mathrm{i}}$ are the proportional, integral and derivative gains of the PID controller of $i^{\text {th }}$ area, $K_{P, i}^{\min }, K_{I, i}^{\min }, K_{D, i}^{\min }$ and $K_{P, i}^{\max }, K_{I, i}^{\max }, K_{D, i}^{\max }$ are the lower bounds and upper bounds of the PID controller.

With the above description, the procedure of applied genetic algorithm for the tested system in this work is given below:

a) Generate randomly a population of parameter strings to form parameter vector.

b) Calculate the fitness function as given in the equation (19) for each Individual in the population.

c) Create Parents.

d) Evaluate the children and calculate the fitness function for each Parent.

e) If the fitness function of the Parents is reached to the maximum value, stop and return; else go to step (c).

Genetic algorithm parameters are taken as given below

The number of population $=50$

The number of generation $=100$

The probability of crossover is 0.8

The mutation function taken is Gaussian

The fitness scaling function is Rank

\section{NERC Standard}

In 1997, the North American Electric Reliability Council (NERC) proposed new control performance standards CPS1 \& CPS2 to evaluate the control area performance in normal interconnected power system operation (Sasaki et al., 2002). 
CPS1: The CPS1 standards replaces A1 criterion. Previously, Control performance criterion (CPC) consists of A1, A2, B1 and B2 criterion. A1 criterion requires that Area Control Error (ACE) return to zero within ten minutes of previously reaching zero. A2 criterion requires that the average ACE for each of the six ten-minute periods during the clock hour is within specific limits referred as $\mathrm{L}_{10}$. Instead of requiring $\mathrm{ACE}$ to cross zero at least once every ten minutes, CPS1 takes a more reasonable approach based upon statistical theory.

First, an expression is identified which represents, quantitatively, a control area's contribution to the reliability objective of the interconnected system to which it belongs. This expression, called the Compliance Factor (CF), is composed of two components, frequency deviation $(\Delta \mathrm{f})$ and ACE. Whenever, a control area has a non-zero ACE and there is a frequency deviation $(\Delta \mathrm{f})$ at the same time, a non-zero CF is formed that could be either positive or negative depending upon the signs of ACE and $(\Delta \mathrm{f})$ at the moment.

Case-I: If $\mathrm{CF}$ is positive, means the control area is acting as a burden to the interconnection's regulation requirement for that particular time.

Case-II: If CF is negative, means the control area is helping the interconnection's regulation requirement.

For each individual clock-minute, a CF value is calculated using the clock-minute average of frequency error and clock-minute average of ACE divided by its bias.

The CPS1 standard requires that each control area must have no less than 100\% compliance (www.nerc.com/online)

$$
\begin{aligned}
& C F_{12-\text { month }}=A V G_{12-\text { month }}\left[\left(\frac{A C E}{-10 B}\right) * \Delta f\right] \\
& C P S 1=\left(2-\frac{C F_{12-\text { month }}}{\varepsilon_{1}^{2}}\right) * 100 \%
\end{aligned}
$$

Where $\mathrm{B}$ is the frequency bias setting $(\mathrm{MW} / 0.1 \mathrm{~Hz})$ and $\varepsilon_{1}$ is a constant derived from a targeted frequency bound and $\Delta f$ is the clock-minute average of frequency deviation, and $\left(\frac{A C E}{-10 B}\right)$ is the clock-minute average of ACE divided by control area's frequency bias.

CPS2: The CPS2 standard requires that the average of ACE for each of the six ten-minute periods during the hour must be within a specific limit referred to as $\mathrm{L}_{10}$ and no less than $90 \%$ of compliance is required.

CPS2 $=\left[1-\frac{\text { Violations }}{(\text { Total Periods-Unavailable Periods) }}\right] * 100 \%$

Violations clock-ten minutes

$=0$ if

$A C E_{a v}=\left|\frac{\sum A C E}{\eta_{\text {samples }-10 \text { minutes }}}\right| \leq L_{10}$

$=1$ if

$A C E_{\text {av }}=\left|\frac{\sum A C E}{\eta_{\text {samples }-10 \text { minutes }}}\right| \geq L_{10}$

Where, $\mathrm{L}_{10}$ is defined as

$L_{10}=1.65 * \varepsilon_{10} *\left(\left(-10 B_{i}\right) *\left(-10 B_{s}\right)\right)^{2}$

\section{Test System}

The proposed GAPID controller for a multiarea power system, described in the previous section, and has been tested on a 39-bus New England system and a 75-bus Indian system (Singh et al., 1995). The Indian power system is in the process of restructuring. As a first step in this process, generation, transmission, and distribution are being separated. The 39-bus system has been divided into two control areas and the 75-bus system into four control areas. For both the systems, three Discos and at least one Genco, having the Poolco based contract, have been considered in each area. The number of Gencos and Discos in the 39-bus system and in the 75-bus system is given in Tables I and II, respectively. A general purpose Governor- Turbine model has been used (Anderson and Fouad, 1984). The SMES unit is included in area-1 in case of 39-bus system and in area-1 \& area-3, in case of 75bus system. PID controller is first tuned using the least square minimization technique to determine the optimal parameters of PID 
controller. Further, the proposed controller is tuned using Genetic Algorithm and the results of GAPID controller has been compared with those obtained by Least Square Minimization (LSPID).

Table I

Control areas in 39-bus power system

\begin{tabular}{|c|c|c|}
\hline $\begin{array}{c}\text { Control } \\
\text { Area }\end{array}$ & $\begin{array}{c}\text { Area } \\
\text { Rating(MW) }\end{array}$ & Market Participants \\
\hline AREA-1 & 400 & $\begin{array}{c}\text { Genco } 1,2,3,4,5 \\
\text { Disco-1,2,3 }\end{array}$ \\
\hline AREA-2 & 500 & $\begin{array}{c}\text { Genco } 6,7,8,9,10 \\
\text { Disco } 4,5,6\end{array}$ \\
\hline
\end{tabular}

Table II

Control areas in 75-bus power system

\begin{tabular}{|c|c|l|}
\hline $\begin{array}{c}\text { Control } \\
\text { Area }\end{array}$ & $\begin{array}{c}\text { Area } \\
\text { Rating(MW) }\end{array}$ & Market Participants \\
\hline AREA-1 & 460 & $\begin{array}{l}\text { Genco } 1,2,3, \\
\text { Disco-1,2,3 }\end{array}$ \\
\hline AREA-2 & 994 & $\begin{array}{l}\text { Genco } 4,5,6,7,8, \\
\text { Disco-4,5,6 }\end{array}$ \\
\hline AREA-3 & 400 & $\begin{array}{l}\text { Genco } 9,10, \\
\text { Disco-7,8,9 }\end{array}$ \\
\hline AREA-4 & 4470 & $\begin{array}{l}\text { Genco } 11,12,13,14,15, \\
\text { Disco-10,11,12 }\end{array}$ \\
\hline
\end{tabular}

\section{Simulation Results}

\section{A. 39-Bus System}

To simulate the 39-bus system, it is assumed that the Discos are also participating in the market along with the generators. If the frequency of the grid falls due to increase in the load in any area, the Discos of the same area are supposed to curtail their loads and the Gencos to increase their generation and vice versa, if frequency of the grid increases.

To implement the Poolco transaction, the Gencos and Discos bids for area-2 are assumed as given in Table III.

Table III

Gencos and Discos bids in area-2 of 39-bus system

\begin{tabular}{|c|c|c|}
\hline Gencos/Discos & Price(Rs./KWh) & Capacity(MW) \\
\hline Genco-6 & 5.0 & 25.0 \\
\hline Genco-7 & 5.3 & 25.0 \\
\hline Genco-8 & 4.9 & 25.0 \\
\hline Genco-9 & 5.6 & 25.0 \\
\hline Genco-10 & 4.7 & 25.0 \\
\hline Disco-4 & 5.2 & 10 \\
\hline Disco-5 & 4.8 & 5 \\
\hline Disco-6 & 5.9 & 5 \\
\hline
\end{tabular}

The bilateral contract considered in the system assumes that the $20 \%$ of Disco-5 (area-2) load demand change will be provided by Genco 6 of the area-2 itself. Assume a change in total load demand of Disco- 5 (area-2) by $50 \mathrm{MW}$ ( 0.1 p.u.) at time $\mathrm{t}=0$ and the change in the load demand of other Discos are assumed to be zero. To meet this change in the load demand, Genco 6 of area-2 will change its generation to 0.02 p.u. $(10 \mathrm{MW})$ to meet the bilateral transactions. Rest of the demand $(40 \mathrm{MW})$ will be supplied by the Poolco transaction. Based on the bids, Genco 8 and Genco 10 change their generations to 0.02 p.u. (10 MW) and 0.05 p.u. (25 MW), respectively, and Disco 5 of area- 2 curtails its load by 0.01 p.u. ( $5 \mathrm{MW}$ ) to implement Poolco transactions. The results of area-2 frequency deviations are shown in Fig.7 (a). This figure also compares the performance of the LSPID and the GAPID controllers. The response of the Gencos 6, 8, and 10 and Disco 5 in area-2, participating in the market, with LSPID and GAPID controllers, are also shown in Fig. 7(b). From these results, it is observed that the performance of the GAPID controller is better than the LSPID controller. The response of Genco-6 is the same as with the LSPID as well as with the GAPID controllers, because Genco-6 is implementing only the bilateral contract by receiving the signal directly from the Disco and not through the controllers. Similarly, Disco-5 receives the signal directly from the SO to curtail the load. Therefore, its response is also the same for both the controllers. 


\section{B. 75-Bus System}

To simulate the 75-bus system, it is assumed that the generators and the loads are participating in the frequency regulation market, and both Poolco and bilateral transactions are taking place simultaneously. Gencos' and Discos' bids of area-2 and area-4 are assumed as given in Tables IV and V, respectively.

Table IV

Gencos and Discos bids in area-2 of 75-bus system

\begin{tabular}{|c|c|c|}
\hline Gencos/Discos & Price(Rs./KWh) & Capacity(MW) \\
\hline Genco-4 & 5.0 & 25.0 \\
\hline Genco-5 & 5.1 & 25.0 \\
\hline Genco-6 & 4.9 & 25.0 \\
\hline Genco-7 & 5.6 & 25.0 \\
\hline Genco-8 & 4.7 & 25.0 \\
\hline Disco-4 & 5.2 & 10 \\
\hline Disco-5 & 4.8 & 5 \\
\hline Disco-6 & 5.3 & 10 \\
\hline
\end{tabular}

Table V

Gencos and Discos bids in area-4 of 75-bus system

\begin{tabular}{|c|c|c|}
\hline Gencos/Discos & Price(Rs./KWh) & Capacity(MW) \\
\hline Genco-11 & 4.9 & 15.0 \\
\hline Genco-12 & 5.3 & 25.0 \\
\hline Genco-13 & 4.8 & 25.0 \\
\hline Genco-14 & 5.6 & 25.0 \\
\hline Genco-15 & 4.6 & 35.0 \\
\hline Disco-10 & 5.0 & 10 \\
\hline Disco-11 & 4.8 & 10 \\
\hline Disco-12 & 5.3 & 10 \\
\hline
\end{tabular}

Different bilateral contracts for area-2 have also been considered. The first contract assumes that 10\% of Disco-5 (area-2) load demand change will be provided by Genco 4 of the area- 2 itself. The second contract is taken between area- 2 and area- 4 and considers that Genco 11 of area-4 will provide 10\% of Disco-5 (area-2) load demand change. The bilateral contracts for Discos in area- 4 assume that the $10 \%$ of Disco- 11 load demand change will be provided by the Genco- 4 of area- 2 and $10 \%$ by the Genco- 11 of area-4 itself and the change in the load demand of other Discos are assumed to be zero.

Assume a step change in load demand of area- 2 by 0.0503 p.u. (50 MW) and area- 4 by 0.0112 p.u. (50 MW) at time t=0. The changes in load demand of area- 2 and area- 4 are met according to their bilateral and Poolco transactions. The power balance in area-2 is achieved as follows.

Genco-4 of area-2 and Genco-11 of area-4 supply $10 \mathrm{MW}$ of power each, through bilateral transaction. SO issues the signal to Genco- 6 and 8 to supply $10 \mathrm{MW}$ and $25 \mathrm{MW}$ of power, respectively, and to Disco-5 to curtail its load by 5 MW. To achieve power balance in area-4, Genco-4 of area-2 and Genco-11 of area-4 supply $10 \mathrm{MW}$ of power each, to meet the bilateral contracts and Genco-11, 13 and 15 increase their generation by $10 \mathrm{MW}, 12 \mathrm{MW}$, and $28 \mathrm{MW}$, respectively, to meet the Poolco based transaction. No Disco of area-4 is selected to curtail its load.

Net change in each Genco is shown in Table VI.

Table VI

Change in the output power of Gencos in MW through bilateral \& Poolco transactions in 75-bus system

\begin{tabular}{|c|c|c|c|c|c|c|c|c|c|c|c|c|c|c|c|c|}
\hline \multirow{5}{*}{ 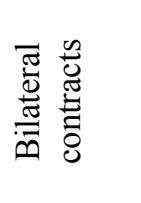 } & & G1 & G2 & G3 & G4 & G5 & G6 & G7 & G8 & G9 & G10 & G11 & G12 & G13 & G14 & G15 \\
\hline & A-1 & & & & & & & & & & & & & & & \\
\hline & A-2 & & & & 10 & & & & & & & & & & & \\
\hline & A-3 & & & & & & & & & & & & & & & \\
\hline & A-4 & & & & & & & & & & & 10 & & & & \\
\hline $\begin{array}{l}\text { Poolco } \\
\text { contracts }\end{array}$ & & & & & & & 10 & & 25 & & & 10 & & 12 & & 28 \\
\hline $\begin{array}{l}\text { Total } \\
\text { Output }\end{array}$ & & & & & 10 & & 10 & & 25 & & & 20 & & 12 & & 28 \\
\hline
\end{tabular}


One of the applications of low capacity Superconducting Magnetic Energy Storage (SMES) to electric power system is to improve the dynamic performance of the power system and this can be shown in the following section. The effect of SMES unit has been analyzed in the present work. Figure 6 shows the frequency deviations in area-1 for 39-bus system and area-2 for 75-bus system with and without SMES unit based on GA tuning PID controller. This figure also shows that the oscillations in the presence of SMES unit are significantly suppressed as compared to without SMES unit. Later on, all the results are with SMES unit.
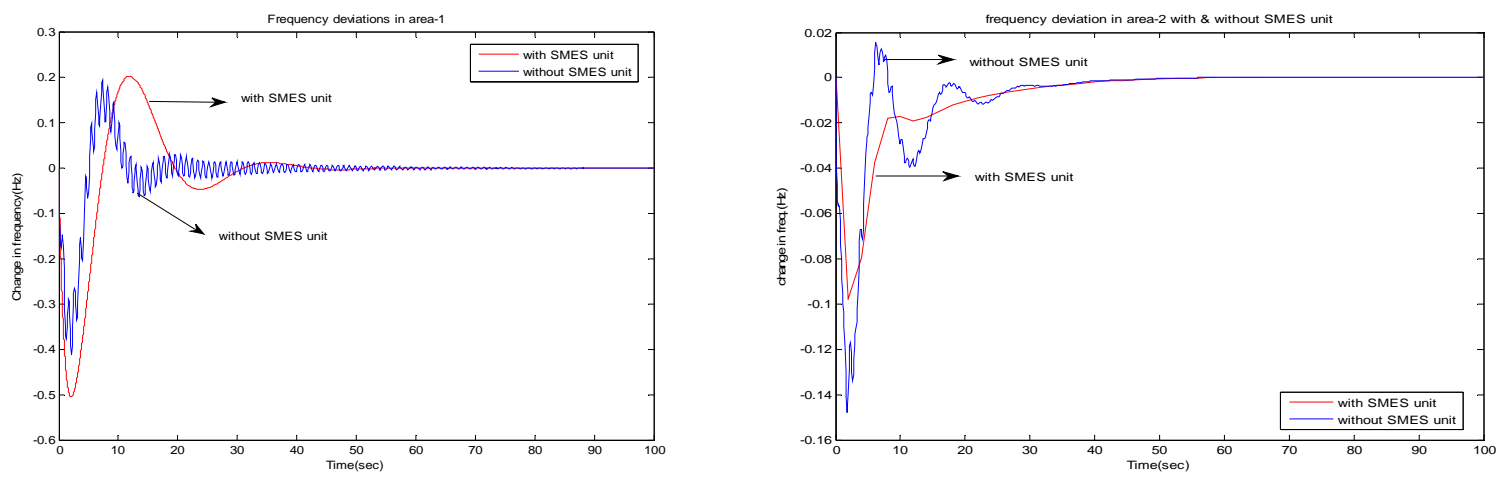

Figure 6 Frequency deviations in area-1 for 39-bus system and in area-2 for 75-bus system.

The results for area-2 frequency deviations are shown in Fig. 7(a). This figure also compares the performance of the LSPID controller and the GAPID controllers. The response of the Genco 4, 6, and 8 and Disco 5 in area-2 and Gencos 11 and 15 in area-4, participating in the market, with the LSPID and the GAPID controllers, are also shown in Fig. 7(b) and (c), respectively.

It is observed from these results that a properly designed GAPID controller works quite effectively. Frequency deviations in all the interconnected areas finally settle to zero and the change in the output of the Gencos of different areas are as per their bilateral and Poolco-based transactions.

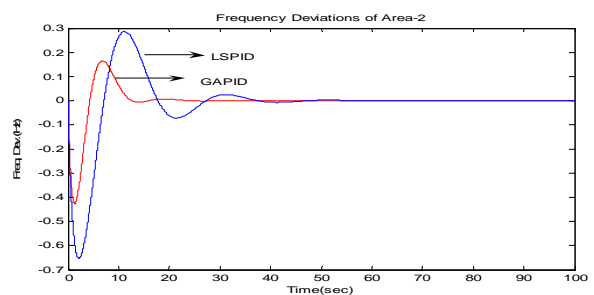

Figure 7(a) Frequency deviations in area-2 for 39-bus system.
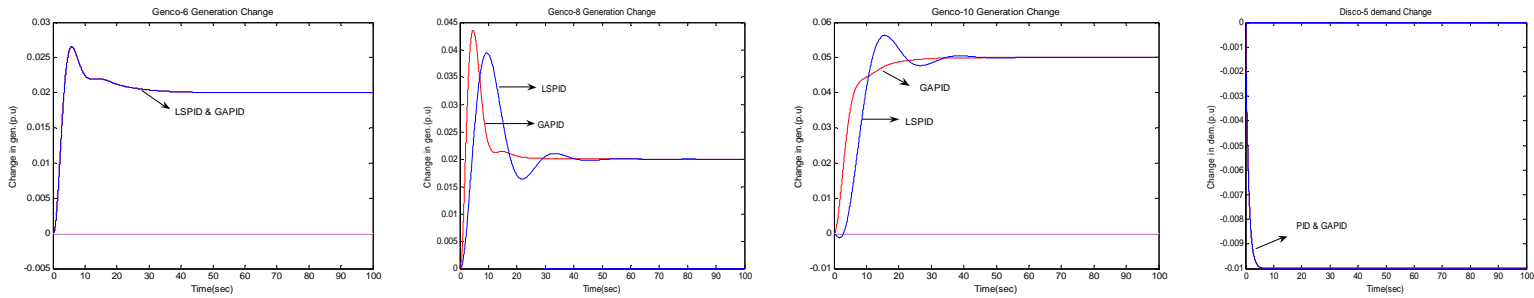

Figure 7(b) Area-2 generation change and load change for 39-bus system.

In Poolco contract, each area demand has been meet out by the generators of the same area, therefore, the tie-line power exchange between the two areas will be zero value. For the bilateral contract between the area-1 and 2, the tie-line power is not settled at zero value but settled according to their bilateral contract between Genco- 6 of area- 2 and Disco- 5 of area-2 itself and it is calculated as follows:

The tie-line power interchange between area-1 and area-2 is $=($ Demand of Discos of area-2 to Gencos of area- 1$)-($ Demand of Discos of area-1 to Gencos of area-2)-(Demand of Discos of area-2 to Gencos of area-2) $=(0.0 * 0.0)-\left(0.0^{*} 0.0 * a_{i j}\right)-(0.1 * 0.2)=$ $0.0-0.0 *(400 / 500)-0.02=-0.02 \mathrm{pu}$

Net tie-line power deviation of area- $2=$ Tie-line power interchange between area- 1 and area- $2=-0.02 \mathrm{pu}$ 


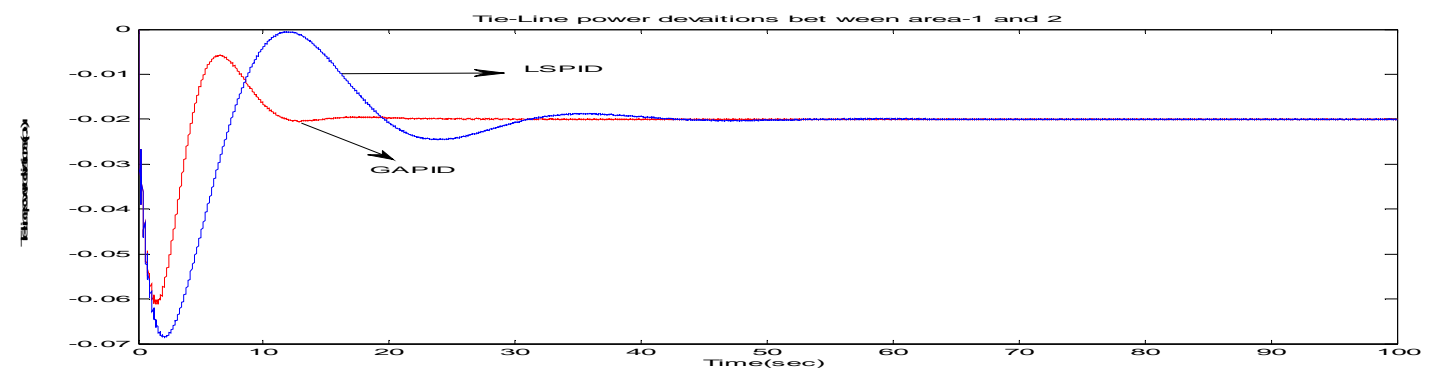

Figure 7(c) Tie-Line power deviations between area-1 and 2 for 39-bus system.
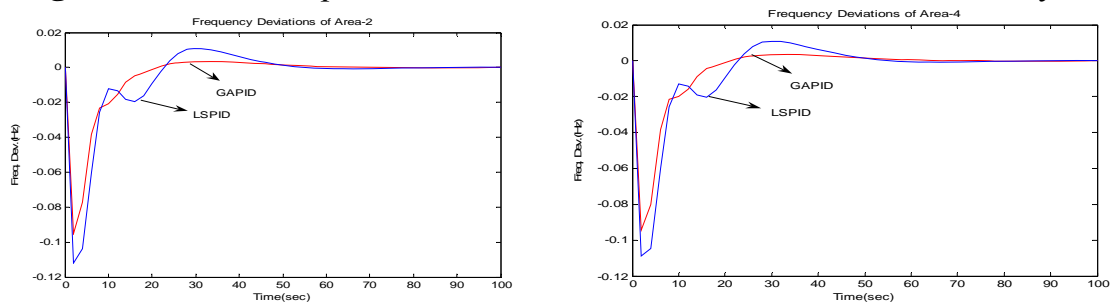

Figure 8(a) Frequency deviations in area-2 \& 4 for 75-bus system.
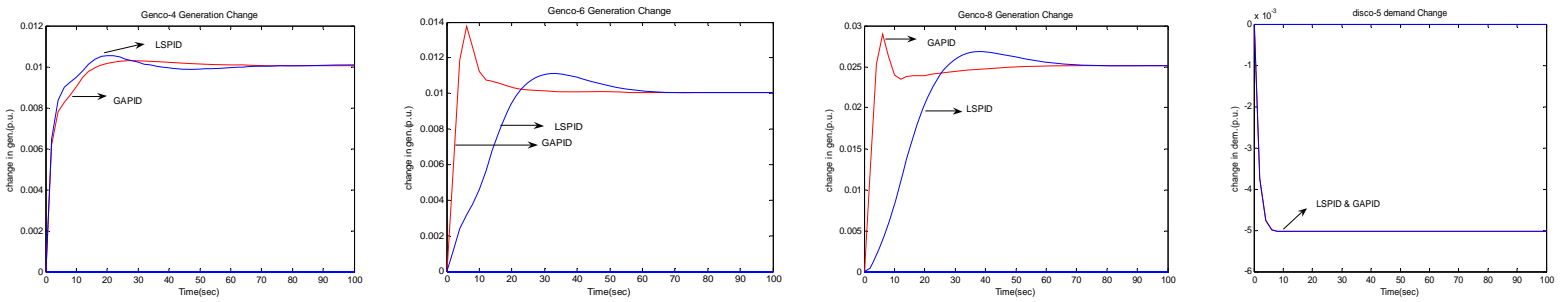

Figure 8 (b) Response of Gencos and Discos of area-2 for 75-bus system.
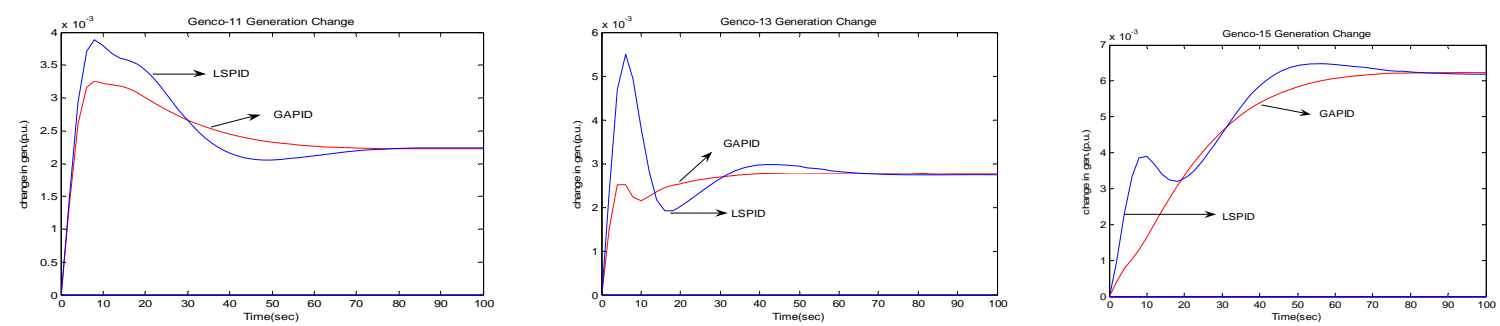

Figure 8 (c) Response of Gencos and Discos of area-4 for 75-bus system.

\section{Compliance with NERC Standard}

Relative compliance of the LSPID and the proposed GAPID controller based AGC schemes to the NERC standards have been established on the practical 75-bus Indian power system. For this purpose, the typical profile of load variation from its scheduled value, for the state electricity network, was taken from the Northern Regional Load Dispatched Center (NRLDC) website(www.nrldc.org/online), recorded for 100 minute on $22^{\text {nd }}$ July,2010, between 17:29:00 to 19:09:00 hours, as shown in fig 9. Since, it was difficult to simulate the load variations for one year; CF for one hour was computed as defined in (20).

In the present work, variation of load in only area-2 has been considered, which is derived from this figure but proportionately modified according to the area-2 rating. Assuming that the response of the controller to the load variations for the year will be similar to that obtained during the sample period of one hour, the CF value so computed has been used to calculate CPS1, as defined in (21). In addition, the CPS2, as defined in (22), has also been computed.

Typical values of $\varepsilon_{10}=0.0025 \mathrm{~Hz}$, and $\varepsilon_{1}=0.0131 \mathrm{~Hz}$ were taken from T. Sasaki and Enomoto et al (2002). Since, only one value of $B_{i}$ was considered in the simulation, $B_{s}$ is taken as $B_{i}$. This gives $L_{10}=6.68 \times 10^{-4}$. Value of $A C E_{a v}$ was computed for the load variations recorded for 60 minutes at 10 -minute intervals.

The values of $A C E_{a v}$ are shown in fig. 10 for LSPID controller as well as GAPID based controllers. Comparing these values with the value of $L_{10}$, it is observed that there is only one violation with LSPID controller and no violation with the proposed GAPID controller. From the violation recorded, the CPS2 was computed for 60 minutes and is shown in fig.11 (a).

Figure 11 (b) also shows the CPS1 values computed for proposed LSPID and GAPID controllers. From these results, it is observed that the proposed scheme is $100 \%$ compliant to the CPS2 requirement and more than $100 \%$ compliant to the CPS1 requirement. 
When compared with corresponding figures for the LSPID controller based AGC scheme, the relative compliance of the proposed scheme is higher.

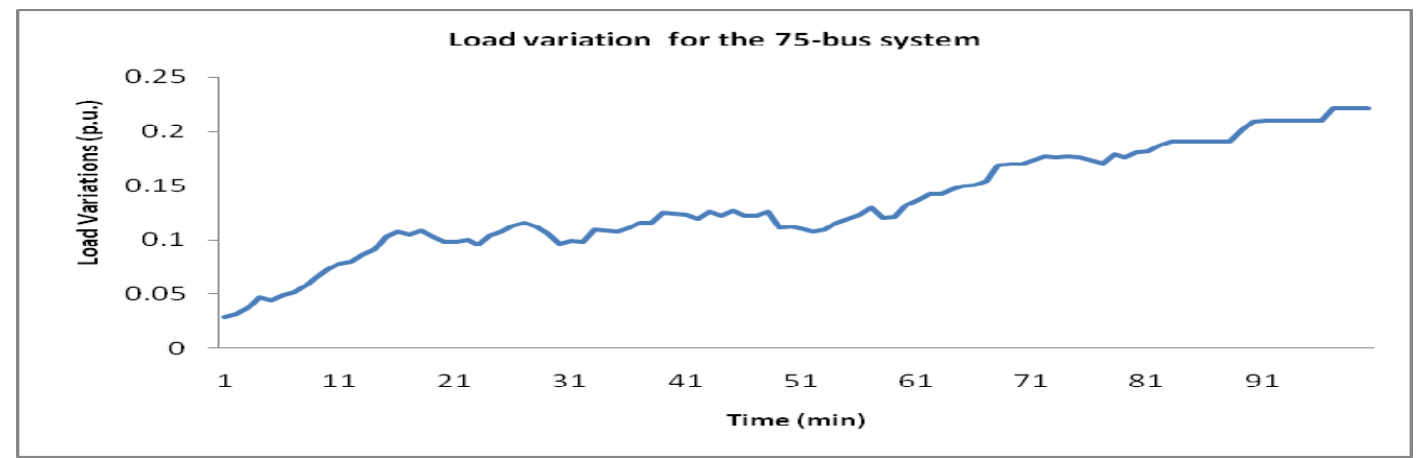

Figure 9 Load variations for the 75-bus system.

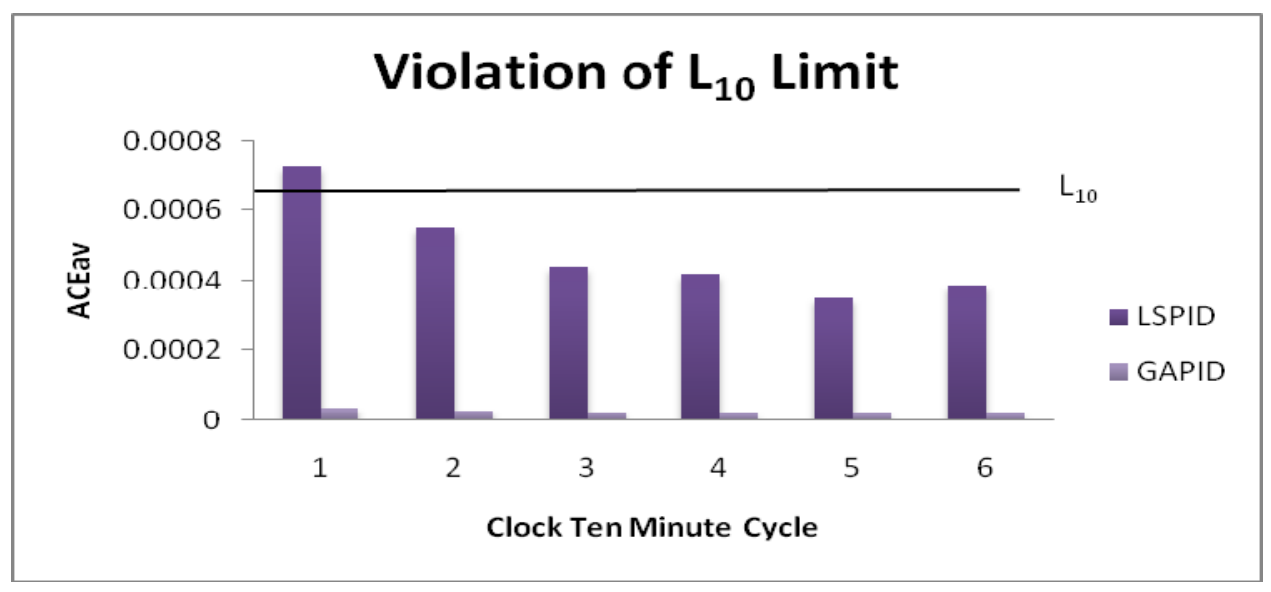

Figure 10 Violation of $\mathrm{L}_{10}$ limit.

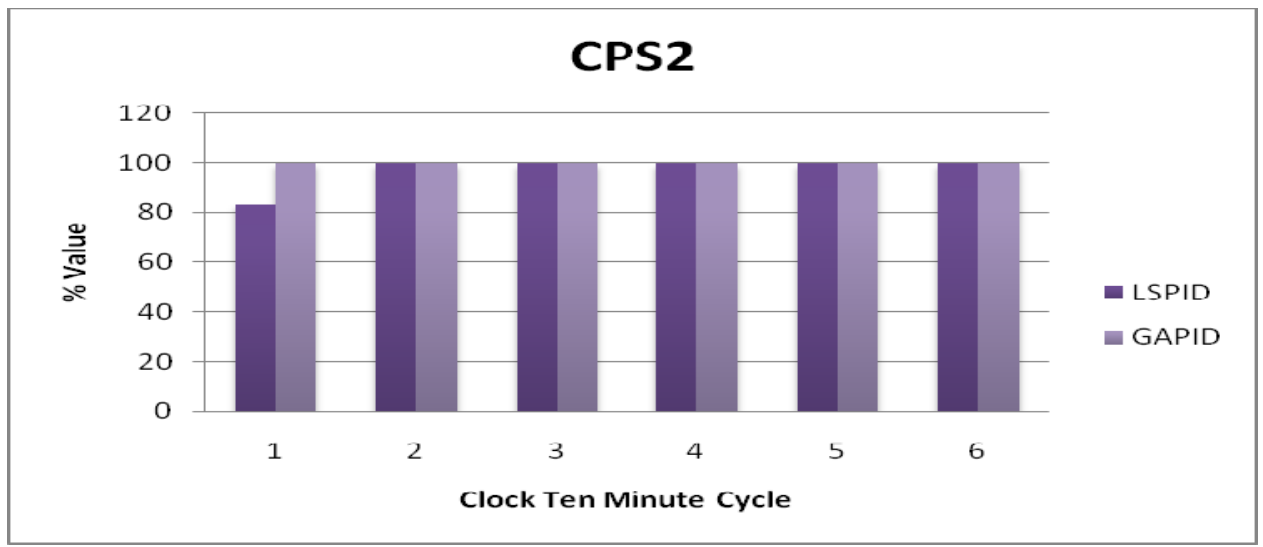

Figure 11(a) Comparison of CPS2. 


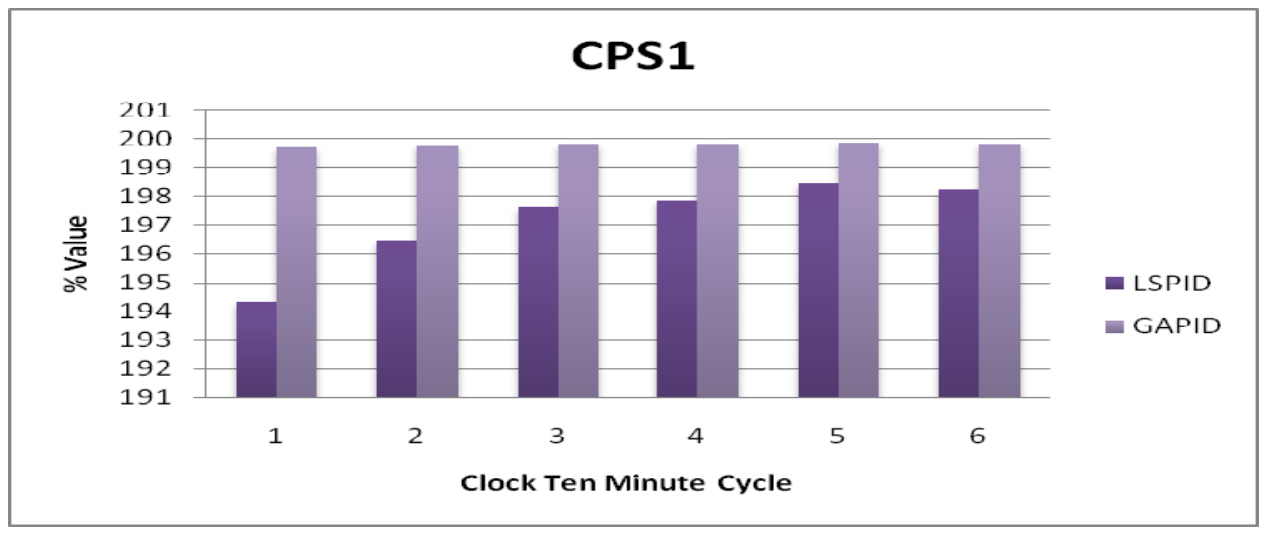

Figure 11(b) Comparison of CPS1

\section{Conclusions}

A Genetic Algorithm based PID (GAPID) controller for multiarea AGC, suitable for the restructured competitive electricity market, has been proposed in this paper to meet the Poolco-based as well as mixed (Poolco \& bilateral) transactions. The proposed controller has been successfully tested on a 39-bus New England system and 75-bus Indian power system for all types of load following contracts. In all the cases simulated, the area frequency error got eliminated in the steady state, and Gencos shared the increase in demand of the area, as per their participation in the frequency regulation market. Results of the GAPID based controller were compared with those obtained with a conventional Least Square minimization approach based PID controller. It is observed that the response of the Gencos for bilateral contracts is the same with both the controllers. For Poolco-based contracts performance of the GAPID controller is better than the conventional PID controller. Effort has been made in this paper to reduce the cost incurred by earlier proposed systems by having SMES unit located in one area in case of two area system and only two areas out of four areas in case of four area system to regulate multi-area frequency.

\section{Appendix}

Table 1. Parameters of PID controller for 39-bus two area power systems

\begin{tabular}{|c|c|c|c|c|c|c|}
\hline \multicolumn{4}{|c|}{ Least Square minimization (LSPID) } & \multicolumn{3}{c|}{ Genetic Algorithm based optimal values of } \\
\hline $\begin{array}{c}\text { Control } \\
\text { Area }\end{array}$ & $\mathrm{K}_{\mathrm{P}}$ & $\mathrm{K}_{\mathrm{I}}$ & $\mathrm{K}_{\mathrm{D}}$ & $\mathrm{K}_{\mathrm{P}}$ & $\mathrm{K}_{\mathrm{I}}$ & $\mathrm{K}_{\mathrm{D}}$ \\
\hline Area-1 & 1.2 & -0.15 & 0 & 0.14884 & -0.37813 & 0.76031 \\
\hline Area-2 & 0.9 & -0.35 & 0 & -0.56927 & -0.73486 & -0.00799 \\
\hline
\end{tabular}

Table 2. Parameters of PID controller for 75-bus four area power systems

\begin{tabular}{|c|c|c|c|c|c|c|}
\hline \multicolumn{4}{|c|}{ Least Square minimization (LSPID) } & \multicolumn{3}{c|}{ Genetic Algorithm based optimal values of } \\
\hline Control Area & $\mathrm{K}_{\mathrm{P}}$ & $\mathrm{K}_{\mathrm{I}}$ & $\mathrm{K}_{\mathrm{D}}$ & $\mathrm{K}_{\mathrm{P}}$ & $\mathrm{K}_{\mathrm{I}}$ & $\mathrm{K}_{\mathrm{D}}$ \\
\hline Area-1 & 0.0 & -0.5 & 0.5 & -0.7412 & -0.4989 & 0.1859 \\
\hline Area-2 & 0.5 & -0.15 & 0 & 1.4524 & -3.0132 & 0.0028 \\
\hline Area-3 & 0.0 & -5 & 0.5 & -0.8090 & -1.9705 & -0.0156 \\
\hline Area-4 & 0.0 & -1 & 0.2 & 0.8975 & -0.1773 & -0.0206 \\
\hline
\end{tabular}

\section{Acknowledgement}

The authors are thankful to the Department of Electrical Engineering, Indian Institute of Technology, Roorkee, for providing the computing facilities to carry out this work. Sandeep Bhongade is grateful to G.S. Institute of Technology \& Science, Indore (M.P) and to AICTE, Government of India for sponsoring him for doctoral research work. 


\section{Nomenclature}

AGC Automatic Generation Control

GA Genetic Algorithm

NERC North American Electric Reliability Council

ACE Area Control Error

SMES Superconducting magnetic energy storage

LSPID Least Square minimization

GAPID Genetic Algorithm based PID values

Genco Generating companies

Discos Distribution companies

SO System Operator

\section{References}

Abdel-Magid Y. L., and Dawoud M. M., 1995. Genetic algorithm applications in load frequency control, Proceeding in IEE Conference Genetic Algorithms in Engineering Systems: Innovations and Applications, 12-14 September.

Al-Saggaf U.B., 1991. An approximate technique to tune PID controllers, Computers \& Electrical Engineering, Vol.17, No. 4, pp313-320.

Anderson P. M. and Fouad A. A., 1984. Power System Control and Stability, IOWA State University Press.

Automatic Generation Control (2005, Apr.). [Online]. Available: http://www.nerc.com.

Christie R.D. and Bose A., 1996. Load frequency control issues in power system operation after deregulation, IEEE Transactions on Power Systems, Vol. 11, No.3, pp. 1191-1200.

Donde V., Pai M. A., and Hiskens I. A., 2001. Simulation and optimization in an AGC system after deregulation, IEEE Transactions on Power System, Vol.16, No. 3, pp. 481-489.

Elgerd O. I., and Fosha C., 1970. Optimum megawatt-frequency control of multi-area electric energy systems, IEEE Transactions on Power Apparatus and Systems, Vol. PAS-89, No. 4, pp. 556-563.

Goldberg D.E., 1989. Genetic algorithms in search optimization and machine learning, reading, M.A: Addison-Wesley publishing. Company, Inc., 1989.

Houck, C.R., Joines, J.A., and Kay, M.G., 1995. A genetic algorithm for function optimization: A MATLAB implementation, Technical report NCSU-IE TR 95-09, North Carolina State University.

Jaleeli N., Ewart D. N., and Fink L. H., 1992. Understanding automatic generation control, IEEE Transactions on Power Systems, Vol. 7, No. 3, pp. 1106-1122.

Joseph R., Das D., and Patra A. 2007. Automatic generation control of an interconnected hydrothermal power system considering superconducting magnetic energy storage, Electrical Power Systems Research, pp. 572-579.

Khamsum C., Pothiya S., Taowklang C. and Sa-ngiamvibool W., 2006. Design of optimal PID controller using improved Genetic Algorithm for AGC including SMES units", in Proc. International Conference on sustainable development: Issues and Prospectus for GMS, December 6-7.

Kumar J., Nag K. and Sheble G., 1997. AGC simulator for price-based operation part-2, IEEE Transactions on Power Systems, Vol.12, No. 2, pp. 527-532.

Northern Regional Load Dispatch Center. [Online]. Available: http://www.nrldc.org.

Sasaki T. and Enomoto, 2002. Dynamic analysis of generation control performance standard, IEEE Transaction on Power System, Vol. 17, No.3, pp. 806-811, August.

Shayeghi H., Jalili A., and Shayanfar H.A., 2008. A robust mixed H2/Hळ based LFC of a deregulated power system including SMES, Energy Conversion and Management, Vol. 49, pp. 2656-2668.

Singh S.N., and Srivastava S.C., 1975. Corrective action planning to achieve feasible optimal power flow solution, IEE Proc., Vol.142, Part C, pp. 572-582.

Tripathy S.C., Balasubramaniam R., and Nair C.P.S., 1992. Effect of superconducting material energy storage on automatic generation control considering governor deadband and boiler dynamics, IEEE Trans. on Power Systems, Vol. 7, No. 3, pp. 1266-1273.

Tyagi, B.,and Srivastava, S.C, 2008. Automatic generation control scheme based on dynamic participation of generators for competitive electricity markets, in Proc. National Power Systems(NPSC), December 16-18, IIT-Bombay.

Yao M., Shoults R. R., and Kelm R., 2000. AGC logic based on NERC's new control performance standard and disturbance standard, IEEE Transactions on Power System, Vol. 15, No.2, pp-852-857. 


\section{Biographical notes}

Sandeep Bhongade (b'1974) received M.E. degree in Electrical Engineering from V.J.T.I. Mumbai, Mumbai University (India) in 2003. Presently, he is a Research Scholar with the Electrical Engineering Department, Indian Institute of Technology, Roorkee (India). His research interests include control system, power system simulation and optimization, and electricity market deregulation.

Barjeev Tyagi (b'1964) received B. Tech. degree in Electrical Engineering from University of Roorkee (India) in 1987 and Ph. D. degree from IIT Kanpur in 2006. Presently, he is a faculty member in Electrical Engineering Department at Indian Institute of Technology, Roorkee (India). His research interests include control system, power system deregulation, power system optimization and control.

H O. Gupta (b'1950) was born in Agra, India. He obtained his B.E. in Electrical Engineering from the Government Engineering College, Jabalpur. He received his M.E. in systems engineering and operation research and Ph.D. from the University of Roorkee in 1975 and 1980 respectively. At present he is working as a professor in the Electrical Engineering Department at Indian Institute of Technology, Roorkee (India). He visited McMaster University, Hamilton, Canada, from 1981 to 1983 as a post-doctorate fellow. His research interests are in the area of computer aided design, reliability engineering, power network optimization and power transformers.

Received March 2011

Accepted May 2011

Final acceptance in revised form May 2011 